\title{
Team Teaching an Interdisciplinary Short-Term Study Abroad Experience: Innovations in Course Design and Collaboration
}

\author{
Carolyn Fabian Stumph \\ Purdue University Fort Wayne \\ Kimberly O'Connor \\ Purdue University Fort Wayne \\ Jonathan Coffman \\ Purdue University Fort Wayne
}

A great deal of research has indicated that study abroad courses offer meaningful and impactful learning experiences for university students. Accordingly, when it comes to course design, it is essential that the study abroad is carefully planned, executed, and delivered in order to maximize the benefits for students. Collaboration is also critical for a successful learning experience. This paper examines an innovative course design which was used successfully in an interdisciplinary, team-taught class for undergraduate and graduate student athletes. The model developed is generalizable to other student populations. The use of this model notably increased student engagement and reflective learning.

Keywords: interdisciplinary collaboration, team teaching, course design, study abroad, student athletes

\section{INTRODUCTION}

Research indicates that study abroad programs can be incredibly beneficial to university students (Mills, Diviney \& Ball, 2010). For example, study abroad programs can help increase students' global awareness, career readiness, and overall academic performance, among many other significant outcomes (Dwyer \& Peters, n.d.). Additionally, among students who study abroad, universities typically experience greater student retention and graduation rates (Education Abroad, 2015). Still, with all of these known benefits, little practical guidance exists for study abroad faculty, even though they are a crucial component of the development and implementation of such courses (Scoffham, \& Barnes, 2009).

This research considers such practical guidance. It explores multiple important elements that should be considered when designing an effective study abroad experience. This design was implemented in the framework of an international trip to Italy. The Italy course was team-taught by faculty from both business and organizational leadership. The course consisted of student athletes ranging from incoming freshman through graduate level, from a variety of different majors. We will highlight the strengths and challenges that we encountered while designing and delivering our 6-week summer course (the first four weeks of the course were a hybrid course, taught prior to departure). Observations related to the value added by our unique course design experience will be discussed, and the practical application of relevant study abroad 
literature will form the basis for our discussion. We address: 1) learning objectives and preparation, which provided academic rigor with the focus on the upcoming trip abroad; 2) pre-trip course design that involved both faculty and students (preparation for travel, team building, the study of destination sites, and related academic/experiential activities); 3) trip implementation, with use of time abroad spent exploring business, legal, economic, historical and cultural attributes of the country; 4) post-trip reflection about the study abroad; and 5) outcomes assessment of the trip by the participating faculty. We conclude with a generalizable model of study abroad course design which may be applicable to a variety of university settings and diverse student populations.

\section{LITERATURE REVIEW}

Recent literature addresses short-term, interdisciplinary study abroad courses - often pointing to their efficacy (Sjoberg \& Shabalina, 2010). For example, research by Gondra and Czerwionka (2018) found that short-term study abroad courses increase intercultural awareness, especially in students who begin the course with lower levels of intercultural knowledge. Similar research further highlights the notion that interdisciplinary study abroad experiences offer a more academically integrated experience where active learning opportunities abroad can culminate in the achievement of a multitude of learning outcomes (Sjoberg \& Shabalina, 2010). Thus, the course design element to study abroad courses is crucial. According to Gardinier and Anderson (2010), "There is no formula for the percentage of time that should be spent in formal class time, seeing cultural/historical sites and events, doing field work, or engaging in peer-to-peer cultural exchange. Regardless of the mix, students should arrive at the destination with a grounding in both the academic and cultural context through a combination of pre-departure lectures, guided research, online discussions, readings, and cultural events relevant to the trip." (p. 26) Beginning with the learning objectives for the course, care and attention should be given, especially to elements such as global awareness and cultural competency, in addition to the actual subject matter that forms the basis of the course. (Mills, Diviney \& Ball, 2010; Sjoberg \& Shabalina, 2010).

Interestingly, to date no known empirical literature has emerged with the idea of collaborative team teaching as a developmental tool for study abroad courses, though many researchers have studied and written about the benefits of collaborative team teaching in general. These benefits can include an opportunity for creativity, diversity of thought, additional interaction with instructors, and enhanced constructive feedback for students, among others (Long et al., 2013; Sandholtz, 2000). In addition, one of the primary benefits of team teaching is faculty development (Sandholtz, 2000). It is against this backdrop that we discuss this novel collaborative topic.

\section{COURSE OBJECTIVES}

Students enrolled in one of three courses as part of this study abroad, since student participants were in several different majors and were either undergraduate or graduate students. As such, three courses were needed to accommodate each individual's plan of study. It was due to this fact that the course was intended from its inception to be team taught by two instructors in two different colleges/schools. One instructor was from the Organizational Leadership department, College of Engineering. The other was from the School of Business. The first two courses were taught by the professor of Organizational Leadership and the third by the professor of Business. The courses titles were as follows with the student population indicated in parentheses:

1. International Leadership, Law and Culture (undergraduate non-business students)

2. Leadership Across Cultural Boundaries (graduate students)

3. Special Studies in International Business (undergraduate business students).

While the students were each enrolled in three different classes, in order to avoid confusion, the instructors made the decision to conduct the course as though all students were in the same "class." Differentiation was required for some of the assessments, but this approach worked very well and contributed to the esprit de corps during the class and travel experience. 
As a team and with the help of the literature, we identified five learning objectives for the class. The course learning objectives, adapted in part from the literature, were:

1. Develop cultural competency and international awareness

2. Apply scholarly literature to direct experiences in Italy

3. Observe and reflect upon historical and contemporary aspects of Italian society

4. Recognize and evaluate Italian responses to contemporary legal issues

5. Identify leadership objectives and business development in the international context.

The first three learning objectives applied to all students, the last two were dependent on the course in which the student was enrolled. These objectives were established by each department and modified for the focus of the study abroad experience.

Prior, detailed planning was absolutely imperative for the success of this course. The learning objectives had to be met in order for the students to receive credit for these classes. The other element that was critical to the success of this undertaking was flexibility. In this case, we took student athletes on the trip. They had an agenda of cultural visits and games which we, as instructors, needed to accommodate. Incorporation of the established agenda into our learning activities and having our learning activities incorporated into the cultural visits in turn, was a key component of the trip's success.

\section{COURSE ACTIVITIES AND ASSESSMENT}

As previously mentioned, the students believed, for all intents and purposes, that they were enrolled in the same class. This required some differentiation of the level of difficulty for some of the course assessments. Due to a lack of country specific expertise on the part of the instructors, we made the decision to reach out across the campus community to faculty and staff who could assist us with various course activities. In one case, we reached out to an etiquette expert in our town who helped educate the students on proper behavior at mealtimes. This was an important aspect of the trip as the students interacted with other players from around the world at meals after each game. Meals in any country but particularly Europe play an essential role in understanding the culture. All of the learning in the course is clearly translatable into their future success as players, coaches, teachers, managers or business people.

The course activities could be classified as falling into five main categories. The accompanying assessments of the learning in those activities are given in parentheses:

1. Pre-departure lectures (online weekly quizzes)

2. Guided research (final research paper)

3. Readings (online discussions)

4. In-country presentations (graded by instructors through use of a rubric)

5. Student journals (graded by instructors through use of a rubric).

We scheduled the course by week as follows:

Week 1: Italian Geography and Art

Week 2: Italian Language, Currency and Culture

Week 3: Italian History and Religion

Week 4: Italian Leadership, Business and Law

Weeks 5 and 6: Travel in Italy.

Most of the weekly lecture featured an expert from campus or the community in addition to any course information on reading, research, discussion, assessments and presentations the instructors needed to share. The featured experts spoke on the following topics:

- Italian art (art history professor)

- The role played by religion in the history, government and business practices of the country (history professor)

- Modern theater, language and culture (theater professor)

- Etiquette expert (community contact).

In addition to these four individuals, we enlisted assistance from the Office of International Education, the registrar and advisors. The experts all provided invaluable insight for the students. Often on the trip the 
students would remark about what one or the other had said. We met in advance with all of the experts so that time was used efficiently and all information delivered was relevant and pertinent. The assemble team was remarkably flexible and accommodating.

We also added in material as the weeks evolved. For example, one of our online class discussions revolved around Dante and the development of the Italian language. This led to discussions of the use of currency as a common "language" and the role of currency more generally as a social arrangement. The week before the trip we arranged a pizza and movie night showing Tom Hanks movie, Inferno. Additions like this were only possible because of the extensive pre-planning that was done. The coaching staff also provided extensive support with logistics which enabled us to focus on the educational matters.

\section{FUTURE CONSIDERATIONS AND CONCLUSION}

The present article addresses team taught short-term interdisciplinary study abroad courses. The course design, activities and assessments discussed herein support the idea that short-term study abroad programs can be an effective way to broaden student learning outcomes and allow students to develop the necessary skills to succeed in today's global marketplace. While team-taught study abroad courses take time to coordinate and develop, the outcomes from the Italy course demonstrate that course objectives were met and highly impactful student learning occurred. Thus, the Italy course may serve as a model for other universities.

Future areas of research may include additional consideration of study abroad course design involving unique student populations, such as student athletes, who may not normally be able to participate in study abroad courses. Additionally, other creative interdisciplinary partnerships for study abroad courses could be explored, including those involving faculty who are not only from different disciplines, but also may be from different universities, countries, or may speak different native languages. From our study abroad experience in Italy, we discovered that collaborative teaching (including partnerships with non-academic units such as athletics), coupled with an interdisciplinary focus, can enhance the quality of the course design and the overall study abroad experience for students.

\section{REFERENCES}

Dwyer, M., \& Peters, C. (n.d.). The benefits of study abroad: New study confirms significant gains. Retrieved from http://www2.clarku.edu/offices/studyabroad/pdfs/IES\%20Study.pdf

Education Abroad. (2015). Washington State University Handbook. Retrieved from https://ip.wsu.edu/oncampus/documents/2015/08/faculty-led-program-manual.pdf/

Gardinier, L., \& Anderson, D.C. (2010, Winter). Learning Abroad. In New Directions for Teaching and Learning (p.124).

Gondra, A., \& Czerwionka, L. (2018). Intercultural Knowledge Development During Short-Term Study Abroad in the Basque Country: A Cultural and Linguistic Minority Context. Frontiers: The Interdisciplinary Journal of Study Abroad, 30(3), 119-146.

Long, J., Johnson, C., Faught, S., \& Street, J. (2013). The need to practice what we teach: Succession management in higher education. American Journal of Management, 13, 73-78.

Mills, L., Diviney, D., \& Ball, B. (2010). Short-term study abroad programs: A diversity of options. The Journal of Human Resource and Adult Learning, 6(2), 1-13.

Sandholtz, J. (2000). Interdisciplinary team teaching as a form of professional development. Teacher Education Quarterly, 27, 39-54.

Scoffham, S., \& Barnes, J. (2009). Transformational experiences and deep learning: The impact of an intercultural study visit to India on UK initial teacher education students. Journal of Education for Teaching, 35(3), 257-270.

Sjoberg, S., \& Shabalina, O. (2010). More Than a Sight-Seeing Trip: Enhancing the Value in Short-Term Study Abroad. Business Education Innovation Journal, 2(2), 43-58. 